\title{
Time for mentally healthy engineering students
}

\author{
Nikkie Korsten \\ Dean's Division \\ Faculty of Engineering \\ Stellenbosch University \\ South Africa, 7600 \\ Email: nikkiekorsten@sun.ac.za
}

\author{
Karin Wolff \\ Dean's Division \\ Faculty of Engineering, \\ Stellenbosch University \\ South Africa, 7600 \\ Email:wolffk@sun.ac.za
}

\author{
M.J. (Thinus) Booysen \\ E\&E Engineering \\ Faculty of Engineering \\ Stellenbosch University \\ South Africa, 7600 \\ Email: mjbooysen@sun.ac.za
}

\begin{abstract}
Mental health issues related to academic stress are experienced amongst undergraduates from different disciplines, with key factors being workload, study skills, resource access and socioeconomic conditions. The status of mental health and well-being of engineering students, globally, has become of increasing concern, but is relatively poorly researched. This paper presents the findings of a faculty initiative at a research-intensive institution in South Africa to determine engineering students' experience of academic stress. Drawing on a holistic educational model, quantitative and qualitative survey results are presented. Key systemic factors are the volume, intensity and distribution of workload, as well as the experience of "information overload" during the Covid-19 pandemic. On the affective front, students provide detailed accounts of the negative emotional impact, which, in turn, contributes to loss of productivity and confidence. The cohort-comparison analysis reveals clear trends across years of study, as well as problem- versus emotion-focused coping strategies. This faculty case study on engineering student experience of academic-related stresses hopes to demonstrate the synergistic relationship between the systemic, affective and, ultimately, cognitive educational support domains for which engineering faculties are responsible. Suggestions are included for ways in which to facilitate improved mental health in our engineering students.
\end{abstract}

\section{INTRODUCTION}

Engineering education has become increasingly complex in recent decades. Contributing factors are the significant shifts in curricula aligned to more holistic graduate competencies, staggering technological developments and globalisation. This is compounded by the challenge of attracting, retaining and graduating greater numbers of students from diverse backgrounds who are able to address 21 st century engineering needs. These shifts have had consequences for engineering educators and students alike, manifesting in increasing workloads and significant stress for both. The dilemma of a heavy workload and pressures to incorporate new, relevant material into the engineering curriculum is not new [1]; faculties worldwide pride themselves on heavy workloads and difficulty that is ingrained in the culture of educating engineers [2]. Attrition rates on engineering programmes [3] may well be exacerbated by the perception that students who cannot deal with the workload and its sacrifices are not suited to engineering [4]. The notion that coping with an immense workload will somehow better equip graduates is seriously challenged by the persistent complaints regarding the lack of key graduate skills and attributes [5], [6].
In addition to workload, a number of factors contribute to increased academic stress, including ineffective methods of studying, restricted resource access and challenging socioeconomic conditions. Such stressors have an impact on retention, performance and overall well-being [7]. More recently, researchers have turned their attention to the effect of academic stress on mental health across disciplines. While there is some indication that increased pressures experienced by engineering students are putting mental health and well-being at risk, research on the topic is remarkably scarce [8]. Given the pressure on engineering educators to prepare well-rounded and capable engineering graduates, and the well established use of student feedback for programme evaluation, a survey of engineering students on their experience of engineering education - and the impact thereof on their mental health could lead to much-needed improvements.

The research study is located in a research-intensive institution in South Africa. Framed within the context of a collaborative continuous-improvement ethic, an engineering faculty research team set out to determine what academic circumstances students find most stressful, how the stress impacts on their cognitive, emotional and practical lives, and what coping strategies students employ to deal with academic stress. The study coincided with the start of the first post-Covid-19 academic year, and was commissioned because of concerns about engineering student progress and performance during the Emergency Remote Teaching (ERT) of 2020. This was considered important in the context of the resource-constrained national landscape, particularly with limited access to ICT and other equipment. This study uses a holistic educational model proposing that educational support should be seen as comprising cognitive, affective and systemic (CAS) domains. In Engineering Education, this means students need to be supported in developing the 'knowing, being and doing' of a future professional engineer. The CAS domains echo not only the holistic view of the curriculum (which includes knowledge, skills and attributes), but also the scope of engineering graduate attributes detailed in the International Engineering Alliance [9] competency profiles. An anonymous, qualitative online survey was distributed to 3000 undergraduate students, with eleven questions designed to elicit possible responses according to the CAS domains. 732 students responded to the survey, and the responses were both qualitatively and 
quantitatively analysed. Methodologically, survey responses were categorised according to these three domains.

This paper contextualises the study and associated methodology. Results are reported, with a particular focus on the analysis of the affective and systemic findings. The paper concludes with suggestions for ways in which to facilitate improved mental health in our engineering students.

\section{BACKGROUND}

Studies in non-engineering disciplines, such as health care, demonstrate that the mental health of students in higher education is a major concern [10], [11]. Although mental health issues are prevalent across disciplines, with different types, conditions and coping strategies, academic related stresses manifesting as mental health issues are of particular concern amongst engineering students [10]. Recent research at a public institution in the US shows that proportionally more engineering students struggle with mental and physical health than their peers: of the undergraduates, $38 \%$ were at high risk of suffering from serious mental conditions such as anxiety, panic disorders, depression and in extreme cases, suicidal ideation [8], [12]. In a survey of $135 \mathrm{HE}$ chemical engineering students in Ohio, $17 \%$ indicated having suicidal thoughts [4]. A study from Australia underscores that students in tertiary technical fields experience higher levels of anxiety and depression than students studying medicine. Concerningly, engineering students were less likely to seek help to deal with mental health struggles [4], [10], [13].

Common systemic academic-related sources of stress across different disciplinary domains are reported as: increased competitiveness, high workload, poor time management [11], poor academic achievement, and lack of resources to deal with academic stressors [14]. Major contributors in the case of engineering students are the hefty academic workload and the difficulty of the courses [8]. In addition, lack of communication and coordination between faculty members can lead to poor workload management, and increases pressures on students, especially around exam times [4]. The added workload challenges of increasingly complex social and sustainabilityfocused (engineering) practice with high levels of uncertainty, together with the expanded engineering graduate competencies and more holistic, fuller curricula [15], have impacted significantly not only on engineering educators who are attempting to keep up with rapid dynamic technological evolution, but most notably on engineering students. As new content is added to curricula, faculty members often take a more conservative approach by not eliminating any course material that they perceive as historically central to their discipline, compounded by a reluctance to drop content related to their niche topics [1]. Today, the traditional, deductive, linear, fundamentalsfirst approaches to engineering education still sees "STEM subjects ... taught in non-overlapping silos" [6](p.11), each bulging at the seams with 'content'. Despite calls for a shift towards a more integrated, learning-centred paradigm that is more likely to equip 21 st century engineering graduates for real-world complex engineering problems, "many faculty members and administrators have resisted change, arguing that the traditional approach has always worked well and needs no major revision" [6](p.8). Working in non-integrated silos and a lack of communication between instructors may also result in similar concepts being taught in different ways within different disciplines, without making the conceptual overlaps explicit. This not only reduces the development of holistic thinking skills in students but also adds unnecessary workload, without contributing to a learning experience and outcome [6].

Conversations among both staff and students are often permeated by the themes of workload and difficulty, conveying worth and status to 'hardship' [2]. A possible side effect is that the learning outcomes themselves are equated with this suffering and hardship [2]. Although a shared experience of hardship can lead to bonding and a shared identity [2], when the pressure becomes too much it can decrease student performance and lead to mental health impairments [4]. These can be exacerbated by parental expectations, financial issues, changes in living circumstances, difficulties balancing work and life [11], lack of identity and sense of belonging [10], as well as family conflicts and poor physical health [14]. In addition, research shows that although experiences of stress, anxiety and depression are generally high among all engineering students, female students were found to suffer even more than the male participants [16], [17].

The mental well-being of students is of vital importance as it greatly impacts learning outcomes and academic success [16]. Although minor academic related pressure can increase performance, too much anxiety can be distracting and debilitating [18]. Ivancevic et al [19] found that there is a positive correlation between student work intensity and student burnout, a reaction to stress. The heavier the workload, the more study-related burnout increases [19]. This state of incessant stress induces a wide variety of emotional, physical and psychological impairments in students, starting off with loss of energy and sense of purpose which transitions into insomnia, utter exhaustion, social dysfunction and depression [19]. Research also found that students respond to perceptions of the learning environment they are in. Student workload perception is highly impacted by the amount of contact hours and frequent assessments. Student workload perception, experienced stress and study approach are highly related [1]. Stress and other negative mental states decrease the cognitive ability of students [18]. Research has pointed out that students who are overly anxious tend to underachieve as their minds are preoccupied with fear [18].

To mediate or moderate stress, students adopt coping mechanisms which in turn impact their learning abilities and academic achievement [18]. Coping strategies are defined as "conscious volitional efforts to regulate emotion, cognition, behaviour, physiology, and the environment in response to stressful events or circumstances" [20]. However, studies conducted among engineering students on how they cope with stress and the effectiveness of coping mechanisms are rare [12]. Early attempts to categorise coping strategies adopt a two-pronged approach: (i) problem-focussed coping, changing 
the situation that caused stress and (ii) emotion-focussed coping, which involves mitigating the emotion that results from the stressor [21]. Balaji et al. [21] authors make a different distinction between two types of coping strategies: active coping (which includes planning, acceptance and positive reframing), and avoidant strategies (which includes denial, behavioural disengagement, venting and humour). Hsieh et al. [18] focus more on disposition of the students to examine the relationship between personal control, action and achievement. They examined students' reactions to academic stressors and show that coping strategies employed are correlated with cognitive beliefs and achievement.

A number of challenges should be taken into consideration when investigating engineering student mental health. As already established, there are not many engineering studies on mental health. Secondly, there is a problem of terminology; there is a deficit in terminology and common approaches to identify mental health challenges and coping strategies which leads to both distinct concepts being used interchangeably [4]. For example, some studies regard drug and alcohol usage as a mental disorder, whereas in our study we define it as a coping mechanism, regardless of it being positive or negative. Thirdly, studies depend on the researcher's personal lens or a particular study context. This study hopes to contribute to a better understanding of engineering student mental health, by engineering educators using a holistic educational framework, in the Global South.

\section{RESEARCH CONTEXT}

This study took place at a high-ranking, research-intensive institution in South Africa, a middle-income country in SubSaharan Africa. The institution has a student to staff ratio of 25 , and a total of approximately 25,000 students. The Faculty of Engineering, which is the focus of this study, offers fouryear contact-based, professional Bachelor of Engineering degrees in the fields of Electrical and Electronic, Mechanical and Mechatronic, Civil, Process (Chemical) and Industrial Engineering, with degrees accredited by the Engineering Council of South Africa (ECSA), a signatory to the Washington Accord. In professional degrees, although classified as undergraduate, students exit at one level higher than a standard Bachelor degree. The faculty has approximately 4,000 students, of which approximately 3,000 are undergraduate, representing many of the country's top school-leaving achievers.

Although the engineering programmes are designed to meet the holistic International Engineering Alliance graduate competency profiles [9], and to regularly integrate relevant technologies and appropriate curricular elements of globalisation and diversity, the faculty has maintained the typical traditional 'fundamentals-first' educational paradigm. This is partially driven by increasingly large classes, with first year cohorts numbering up to 1000 students in a single course. It is common for a lecturer to be responsible for 200-300 students in one of up to three courses. A typical engineering Bachelor's degree curriculum entails an annual credit-load of 150 (which translates to 1500 notional hours over 26 weeks of each year). To place this workload in context, the average USA and EU curricular workloads are 1800 and 1680 hours per year respectively.

Tuition fees for engineering degrees are considered to be high at approximately ZAR60,000 (US\$4100) per year, which is approximately $80 \%$ of the country's median GDP. Although the country's official unemployment figure is already high at $36 \%$, it is $46 \%$ for those between the ages of 18 and 34 [22], unless they have a degree. Only $1.8 \%$ of the country's 7.2 million unemployed have graduate degrees [22]. Although there are financial support systems in place for tertiary studies, the country's social assistance system is beset by challenges [23]. These factors, combined with a serious shortage of engineering skills in the labour market, result in engineering students experiencing substantial socioeconomic pressures to successfully complete the engineering degree once started. However, the completion rate of the four-year engineering Bachelor's over eight years is approximately $70 \%$. Completion within minimum time is under $50 \%$, which is well aligned to other South African research-intensive institutions [3], and overall throughput.

Given these retention and throughput challenges, the faculty is actively engaged in programme renewal and staff capacity development initiatives. These initiatives are designed to improve engineering education to better meet the urgent national shortage of engineering skills in the labour market. The onset of Emergency Remote Teaching (ERT) [24] during the Covid19 pandemic, and subsequent shift to augmented forms of learning during 2021, raised concerns in the faculty around how the diverse body of students is coping.

\section{THEORY AND METHODOLOGY}

As part of the institutional capacity-building mandate, engineering staff are supported in conducting engineering education research (EER) initiatives, which are covered by impact evaluation ethical clearance [ING-2020-14765]. The faculty has adopted a holistic overarching model which both differentiates between and integrates the various curriculum, teaching, learning and assessment dimensions. At the curricular level, care is taken to identify epistemological (knowledge), ontological (being) and praxis (skills) elements [25], which are linked to Bloom's cognitive, affective and psychomotor learning domains (1956), and enabled through effective cognitive, affective and systemic support [26]. This differentiation has helped in the development and scaffolding of more active project-based, case-study-based and peer learning strategies, for example. Staff can interrogate how effect the learning materials are for cognitive support, how effective the systems are for enabling access and engagement, as well as how students respond (affective) to the strategies.

The CAS-model [27] has effectively been applied to evaluate postgraduate learning and impact on student identity and well-being [28]. Similarly, the model was applied to a national engineering educator survey on the impact of the sudden shift to ERT [29]. Both studies indicated a synergistic 
relationship between the systemic (workload and informationoverload) and affective (health and stress-related) dimensions of academic work. With the continued impact of the pandemic on education, and the onset of a second year (2021) of augmented online teaching in a contact-based institution, it became essential to determine how the undergraduate engineering students were experiencing this unprecedented form of learning.

An interdisciplinary research team, comprising engineering and sociology academics, designed a survey instrument based on the CAS-model to investigate "how students experience and manage academic-related stresses". Using a deductive approach, questions were designed to reveal cognitive, affective and systemic factors. The anonymous online survey consisted of 11 qualitative questions and all undergraduate students were invited to voluntarily complete the survey during the course of the first month of the first semester of 2021 (March). The response rate was $n=732$, with all participants consenting to their anonymised data being used for research purposes.

Microsoft Forms was used to present the survey and aggregate the response data into Microsoft Excel files, from which the results were analysed. The metrics relating to stressful scenarios (Figure 1) were captured using a Likert scale and were aggregated for all the respondents for each of the scenarios, for which percentages were calculated for each scenario according to the reported classifications attributed to Extremely stressful, Stressful, Neutral, Manageable, and Enjoyable. To assess the coping strategies (Figure 2), the variables (drawn from similar international surveys) were aggregated per cohort, and percentages calculated. The students were able to select as many coping strategies as they wanted. Accordingly, this metric was calculated as a percentage of the number of respondents from a cohort who chose the option. A temporal change (delta) from the first two years to the last two years was calculated with average(3:4)-average(2:1).

This paper presents both the quantitative survey results, and the affective and systemic analysis of qualitative student responses to three particular questions: (1) How does academicrelated stress make you feel? (2) How does academic-related stress affect your ability to work? (3) What are your personal methods to relieve academic-related stress?

\section{FINDINGS}

\section{A. Stress scenarios}

The findings presented in this section begin with the identification and scope of 'academic-related stresses'.

Figure 1 shows the breakdown of typical learning scenarios and gives an indication of the reported level of stress associated with each of these. The activities have been sorted according to an incremental proportion of students, from all cohorts, finding the scenario either stressful or extremely stressful. Typical 'transmission mode' [30] learning scenarios in a classroom setting were considered to be least stressful (13\% of students). Online learning was considered slightly more stressful than face-to-face (17\% of students). Doing individual projects and attending tutorials, which tends to be more theoretical and paper-based than practicals, were considered stressful by $24 \%$ and $26 \%$ of students, respectively. This increase in reported level of stress from passive to more interactive learning experiences is probably due to the more active sessions contributing to their marks. Taking part in practicals, in which the students make the transition from the theory to practical implementation, the stress levels increase: $33 \%$ of students considered doing practical tasks to be stressful. Taking part in group work and group projects apparently introduced more stress, with $36 \%$ and $43 \%$ of respondents respectively rating these scenarios as stressful. Almost $50 \%$ of the students find writing reports stressful. The two forms of examination, namely practical and written examinations are reported as causing the most stress. Practical examinations, in which the students are typically expected to demonstrate practically the solving of some problem, was stressful for $59 \%$ of the students. Written examinations, which is the nominal form of major individual assessment and typically accrue the lion's share of marks, were considered to be stressful by $68 \%$ of the students.

In the qualitative section on stress scenarios, we report on what students describe as the most stressful, with a significant number of responses being classified as systemic factors. The following section presents a number of typical examples drawn verbatim from the textual responses. The volume, intensity and distribution of workload, as supported by several international studies, is indicated as a major stress factor and contributor to mental health impairments:

Quote: The quantity of the work. So much work. It is difficult to find the balance and when I do take a break, I keep thinking and stressing about how much work I still need to catch up on. Always behind on work even though I work so so much!

Quote: Not being able to gauge how fast I should be getting through my work and falling behind. (Q411)

In addition to the generally high workload, students report perceptions of inconsistent, confusing and short-notice communication as additional and unnecessary burdens:

Quote: Not always knowing what my schedule will be like. I feel like if I have a complete schedule where I know exactly what is happening each day, I would cope better. I find it stressful constantly having to look up to see if things have changed. (Q204)

Quote: Organizing everything and I am scared that I will miss a test because all of the information is so scattered (Q325)

Quote: TEST WEEK. Multiple tasks/pracs from different modules to be handed in in the same time span. Not being able to work on everything at the same time (being superhuman?) (Q99)

These systemic challenges such as communication and workload management have been amplified in the context of ERT during the pandemic, a situation in which lecturers and students alike had to adjust to online and hybrid learning. In a separate survey [29], staff confirm the sense of being overwhelmed: 


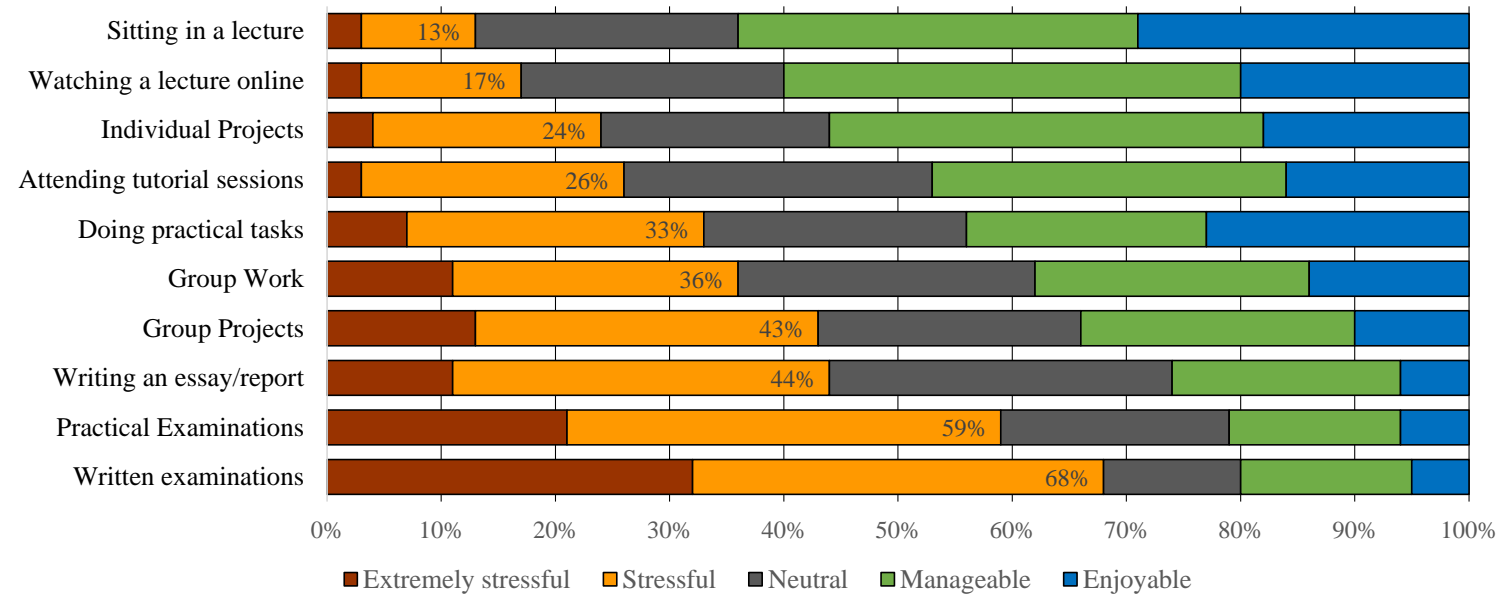

Fig. 1. Learning scenarios and indicated stress by undergraduate engineering students.

Quote: (ERT Staff) I got very overwhelmed by all the emails ... because it was like drinking from a firehose

\section{B. Emotional impact}

The first qualitative question on how academic stress 'makes you feel' reveals that the systemic factors contribute significantly to affective challenges. Some students indicate general levels of emotional distress such as anxiety and depression:

Quote: I feel like I should just give it all up. (R615)

Quote: Mentally tired and depressed. (R589)

This distress may manifest physiologically and psychologically [19], with several students reporting the impact on eating behaviour, feeling nauseous, and sleep patterns. The physiological experience of stress extends to the psychological:

Quote: Like crying. Sometimes I feel I don't deserve to be in this course. (R532)

Quote: I feel extremely nervous and get more aggressive or frustrated at minor inconveniences. Sometimes I can also become quite despondent or depressed if I feel overwhelmed. (R674)

The experience of emotional, physiological and psychological stress has a significant impact on students' ability to work effectively, with many students describing taking far longer to complete tasks, but also completing these without a sense of efficiency. Perhaps the most concerning impact is that of loss of confidence and a diminished view of their future:

Quote: It makes me doubt my abilities at times and makes me feel like maybe I'm not a "real" engineering student (R653)

Quote: The heavy workload is what is spoiling the fun for me. In my first year, I used to enjoy my work, but because of the workload, I no longer enjoyed the work, which was in itself a stressor, because now I started doubting my choice of degree. (Q160)

\section{Coping strategies}

As noted in the background section, perspectives on coping strategies are dependent on a particular lens. For the purpose of this paper, coping strategies indicated by students are reported using the concepts of 'conducive to' and 'not conducive to' productivity and mental health. It is worth noting that these are all self-reported results, which may result in under-reporting of certain coping strategies, despite the anonymity of the survey.

More than $45 \%$ in each cohort engage in the three coping strategies which are considered conducive to good mental health, namely sleeping, exercise, and talking to someone. However, their engagement reduces by $6 \%$ and $13 \%$ respectively for Sports/Exercise and Talking to someone for students further along on the four-year programme (Fig. 2). The first six coping strategies show an increase across cohorts from the first to fourth years of study. Contrary to the three oftencouraged strategies on the right side of the graph that either stay flat or decline with seniority, the first six strategies show a marked incline with years of study. Of these, the strategy most often employed is eating, which is employed by $41 \%$ of all the students. The next strategy, used by $26 \%$ of the students is Computer Games. This was followed by medication, which was reported by $26 \%$ of the respondents. The increase of this strategy was 15 percentage points, but significantly, 11 of those was from the first to the second year. This result warrants further investigation, since preliminary probing showed the bulk of these to be anxiety-related. The last three strategies were Drinking (13\%), Shopping (7\%) and Drugs (5\%). The increase across the four years of study per cohort is clear: use of alcohol and drugs respectively increase by 12 and 5 percentage points.

\section{DISCUSSION}

The 732 student responses to the anonymous academic stress survey confirm global reports of the impact of systemic factors (such as high workload, personal time and work management practices, and communication systems) on mental health. The affective impact can be summarised as emotional, physiological, psychological and sociological - the sense of a loss of identity as a potential 'engineer'. What is highly 


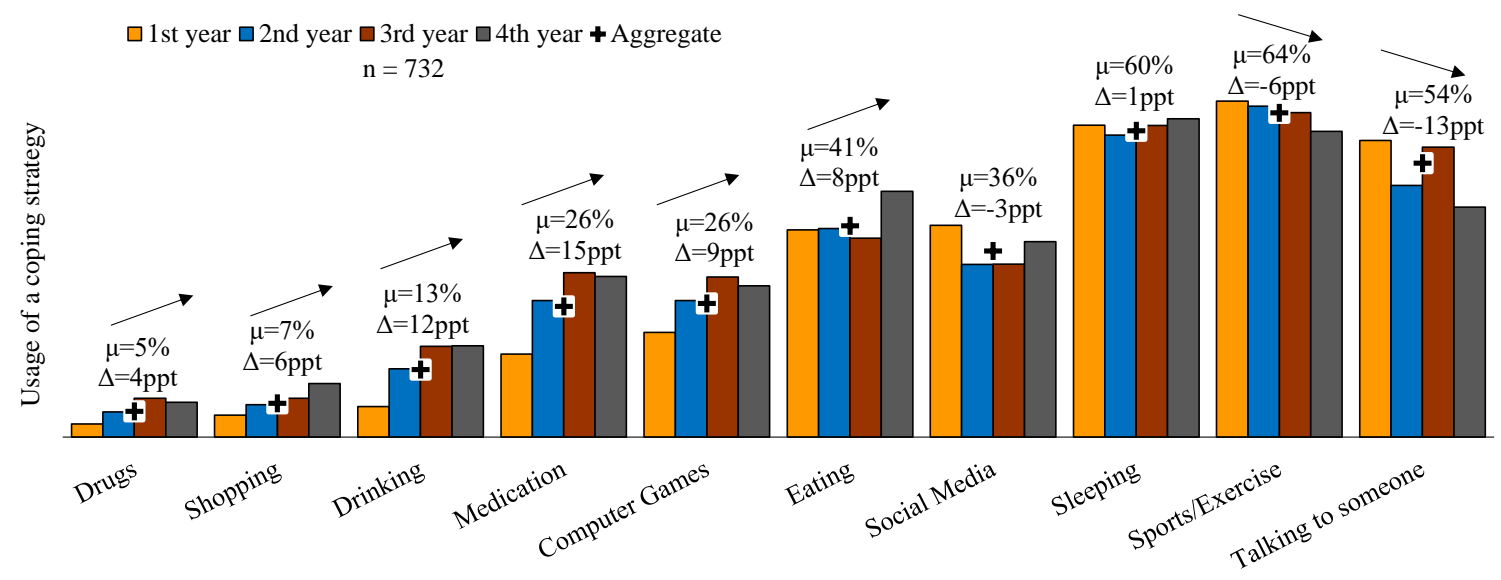

Fig. 2. The strategies used by students to cope with the demands of engineering studies.

significant, however, is the synergistic relationship between the systemic, affective and cognitive domains of learning support. Given that the educator's mandate is to enable 'epistemic access' [31] - in other words, cognitive development - the systemic and affective impact on the cognitive is clear in a number of student responses:

Quote: The workload hinders your ability to actually explore a module's subject matter (Q239)

Quote: The crammed schedule. So many new things to learn that there is hardly time to really grasp a concept well enough to enjoy it. (Q372)

The attempts to alleviate stress, drawing on a range of coping strategies, could be described as either 'active' or 'avoidant' strategies [21]. However, engaging in sport, for example, could be considered both: on the one hand, taking time out to exercise may appear to be 'avoidant' in that the student is not actually engaged in academic work. This 'timeout' activity may simultaneously be enabling the student to reflectively and subconsciously process information or concepts. The same could be said for coping strategies such as computer gaming. For the purpose of this discussion, the coping strategies are discussed using problem-focused versus emotion-focused strategies.

\section{A. Problem-focused}

If we were to take a problem-focused approach, student voices in relation to coping with the workload give us some direction. Some students describe their own active problemfocused strategies, implementing conducive time management measures, and even health-related practices:

Quote: I try my best to calm down so that I will be able to concentrate I drink a lot of water I take vitamins like omega 3 and try to stay positive. (V7)

Quote: I run/exercise. Exams are different to on going projects because even if I procrastinate studying for an exam and then cram the night before, after the exam is finished there nothing I can do change it and it's actually done. This usually is a big relief and will motivate me to make use of healthy coping mechanisms instead of my typical avoidance strategies. (V9)

An interesting observation - in light of the 'self-regulated learning' graduate attribute that is intended as part of the engineering qualification - is the fact that a significant number of students ask for assistance in establishing problem-focused strategies:

Quote: I really think if we could be helped or taught of time management relating to studies we would be good,because for now another major stress is a heavy workload, like our day to day schedules are congested but nevertheless it's part of Engineering. (W238)

Quote: Help guide with time management, this will help students create priorities and allow them to focus on modules/tasks at the correct time. (W678)

Quote: To be honest, I am not sure; I am aware that the faculty and university have resources available to help students, but I've never attempted to make use of it. I feel like I would just be told what I already know - 'improve your time management, get enough sleep, eat well, exercise and ask for help'. (W271)

\section{B. Emotion-focused}

Students acknowledged that the faculty and institution does indeed offer such assistance. However, similar to global trends reported by Hsieh et al. [18], support was perceived as having a problem-focused approach, while students expressed the need for emotion-focused support:

Quote: When seeking out help through the psychologists ...I felt that my problems weren't viewed as 'bad enough' to require attention and general solutions were given when all I needed was to talk through it. (W220)

Quote: the pace of the work is unbearable and the psychological help offered doesn't help as they only focus on helping you with timetables and planners. Need resources to help manage mental exhaustion. (W694) 
This emotion-focused need extends to specific requests for mental health support:

Quote: Put more emphasis on mental health and what to look out for as signs that your mental health is declining and how to handle trying to restore your mental health while not falling behind and handling your workload. (W316)

... which could be partially addressed through a problemfocused approach, as in the following student's suggestion:

Quote: I would say that as a student I feel that it takes a lot of courage to ask for help when one is under immense stress. Maybe the department could start an online platform where students anonymously share their experiences of academic-related stress and what they do to cope with it,... I feel this way students may feel less intimidated to ask for help (W243)

The reference to courage and lack of confidence permeates many of the student responses. Lack of confidence has implications for effective learning, programme retention and academic success. Several student suggestions imply a synergistic relationship not only between the CAS factors, but also between problem- and emotion-focused coping strategies:

Quote: I try to set emotional boundaries in terms of how much I'm willing to sacrifice for a module. I try to sleep enough during exam season to stay fresh. So if 10pm rolls around, no matter if I still have work left to study, I go to bed. (V680)

Self-regulated learning and productive problem- and emotion-focused strategies are key to confidence-building [18]. Students who appear to be more 'confident' refer to the academic stresses as 'necessary evils':

Quote: Unfortunately academic stress is just one of those things that you need to learn to deal with. If you want to succeed then you can't buckle under the pressure. (W704)

Quote: I personally believe not much. Stress is something we will have to cope with throughout our life, every individual must find their own way to cope through stressful times. (W691)

Quote: I take it in my stride, I've accepted that it is part of the engineering degree experience. All one can do is limit the stress factors whenever possible (R620)

It is important to note that two key limitations of this study are the question of alternative coping strategies (such as 'spirituality') and socio-economic factors. Research shows that students from economically disadvantaged backgrounds are more likely to experience symptoms of anxiety and depression during their studies [17]. The anonymity of the survey means that no student profile data were gathered, specifically to enable students to honestly reflect on the questions without fear of judgement. The research study being at a higher education institution in a South African context, however, does need to take socio-economic factors into consideration. Some indications in the current data point to socioeconomic factors where students refer to financial constraints and the pressure to achieve a certain mark to keep a bursary as a major stressor. For example:
Quote: Most stressful: Paying for my studies (Q676). Feeling: Well not good at all. Knowing your studies are not paid is not a great feeling (R676)

Quote: Most stressful: Constantly worrying that I will lose my bursary if I fail, well I did fail and now I am on the verge of losing it. (Q291)

Quote: Most stressful: Getting 65+ aggregate so I can qualify for a bursary (Q326)

\section{Accountability}

Engineering is defined as a field which focuses on the "analysis of problems and synthesis of solutions" [32]. As such, engineers are naturally inclined to 'problem-focused' approaches. The institution, in this case study, has adopted problem-focused solutions by providing time management and study skills workshops, as well as improving communication coordination and platform alignment. To a certain extent, there is also provision of psychologists and access to emotionfocused support. However, these support services are generally located beyond the faculty itself.

Discussion with faculty management on the survey results raised the question of accountability. Massification and increasing diversity in Higher Education systems globally has seen a significant shift in the response to student support needs over the past three decades. The perception that many first-generation, previously disadvantaged students were not succeeding in $\mathrm{HE}$ as a result of academic literacy practices saw the initial outsourcing of support to Academic Literacy or Language Support units [33]. Similarly, this is the current approach to emotion-focused support. In the case of academic literacy support, the awareness gradually developed that success in HE required more than literacy development, and additional support systems evolved to include orientation, study skills and diversity training. Today, academic literacies are increasingly integrated into the mandate of disciplinespecific lecturers. However, requiring such a lecturer to be 'responsible' for the scope of the affective impact on his/her students is not realistic, given the lack of appropriate psychological or counselling training. In addition, faculty:student and counsellor:student ratios in resource-constrained environments do not provide the capacity to guarantee effective support [4]. Even though lecturers are closest to their students and most ideally positioned to also provide emotional support and meet the affective needs of students, this is not realistic in largeclass contexts. As other research within the faculty has shown, many lecturers are trying to cope with a heavy workload themselves whilst managing additional stresses as a result of hybrid augmented remote teaching. As a result of these circumstances, lecturers indicate having developed greater sensitivity to student working conditions, and have implemented more streamlined problem-focused communication strategies. Explicit empathetic, emotion-focused awareness emerges in student feedback, such as:

Quote: I also wanted to let you know that the little snippets of bloopers, jokes, puns and just humour you've left/put in the lectures really lightened the stress a lot. In 
the state the world is in now it really helped a lot to know that lecturers are also struggling alongside us with putting the study material together. Made me feel much more connected to my studies and for that I am very grateful.

The global literature on engineering student workload, however, suggests that where lecturers could make a difference is to begin with a problem-focused approach to collectively address the systemic conditions that currently appear to exacerbate students' affective educational experience. Such an approach would need to take the context of globally-aligned engineering qualification standards into account. This warrants further research. We suggest that such action would be mutually beneficial as it could potentially address student and staff workload and pressure in the longer term. Addressing these through a problem-focused strategy simultaneously impacts on the emotional experience, and potentially increases academic success and well-being.

\section{CONCLUding COMMENTS}

This paper presents the findings of a faculty-wide study on how engineering students at a research-intensive institution in South Africa cope with academic-related stress. Using a holistic educational support model comprising cognitive, affective and systemic dimensions, the findings of an anonymous online survey are presented and analysed. Key systemic factors, as in several international studies, appear to be the volume, intensity and distribution of workload, as well as the experience of "information overload" during the ERT period. On the affective front, students provide detailed accounts of the negative emotional impact, which, in turn, contributes to loss of productivity and confidence, as has been the case nationally and globally [34]. The faculty case study on engineering student experience of academic-related stresses hopes to demonstrate the synergistic relationship between the systemic, affective and, ultimately, cognitive educational support domains for which engineering faculties are responsible. A global picture is emerging of the impact on engineering students of an overfull curriculum, increasingly complex educational conditions and societal expectations. The discussion draws on problem- versus emotion-focused approaches to addressing the impact of stress, and suggests that there needs to be a recognition of the relationship between two such approaches. Given the $\mathrm{HE}$ mandate to enable the holistic development of engineering graduates, the time has come for us as engineering educators to better support mentally healthy engineering students.

\section{REFERENCES}

[1] D. Kember and D. Leung, "Influences upon students' perceptions of workload," Educational Psychology, vol. 18, pp. 293-307, 1998.

[2] E. Godfrey and L. Parker, "Mapping the cultural landscape in engineering education," Journal of Engineering Education, vol. 99, no. 1, pp. 5-22, 2010.

[3] S. Shay, K. Wolff, and J. Clarence-Fincham, "New generation extended curriculum programmes: Report to the DHET," University of Cape Town, Tech. Rep., 2016. [Online]. Available: http://dx.doi.org/10.13140/RG.2.1.3135.5767
[4] A. Maxson and D. L. Tomasko, "Supporting the mental health and wellness of chemical engineering students at the department and college levels," ASEE Annual Conference and Exposition, Conference Proceedings, vol. 2020-June, 2020.

[5] R. M. Felder, "Engineering education: A tale of two paradigms," 2012.

[6] - "Stem education: A tale of two paradigms," Journal of Food Science Education, vol. 20, no. 1, pp. 8-15, 2021. [Online]. Available: https://onlinelibrary.wiley.com/doi/abs/10.1111/1541-4329.12219

[7] R. Cobo-Rendón, M. V. Pérez-Villalobos, D. Páez-Rovira, and M. Gracia-Leiva, "A longitudinal study: Affective wellbeing, psychological wellbeing, self-efficacy and academic performance among first-year undergraduate students," Scandinavian Journal of Psychology, vol. 61, no. 4, pp. 518-526, 2020. [Online]. Available: https://onlinelibrary.wiley.com/doi/abs/10.1111/sjop.12618

[8] A. Danowitz and K. Beddoes, "Characterizing mental health and wellness in students across engineering disciplines," in 2018 CoNECD - The Collaborative Network for Engineering and Computing Diversity Conference. Crystal City, Virginia: ASEE Conferences, April 2018. [Online]. Available: https://strategy.asee.org/29522

[9] "IEA Graduate Attributes and Professional Competency Profiles," International Engineering Alliance, Tech. Rep., 2013. [Online]. Available: https://www.ieagreements.org/

[10] B. Coley and M. Jennings, "The Price of Persistence: Investigating the Impact of Pursuing Engineering on Undergraduate Student Mental Health," Proceedings - Frontiers in Education Conference, 2019.

[11] K. J. Reddy, K. R. Menon, and A. Thattil, "Academic stress and its sources among university students," Biomedical and Pharmacology Journal, vol. 11, no. 1, pp. 531-537, 2018.

[12] N. Johnson-Glauch, L. A. Cooper, and T. S. Harding, "Goal setting as a means of improved mental health outcomes for materials and mechanical engineering students," ASEE Annual Conference and Exposition, Conference Proceedings, vol. 2020-June, 2020.

[13] C. M. Leahy, R. F. Peterson, I. G. Wilson, J. W. Newbury, A. L. Tonkin, and D. Turnbull, "Distress levels and self-reported treatment rates for medicine, law, psychology and mechanical engineering tertiary students: Cross-sectional study," Australian and New Zealand Journal of Psychiatry, vol. 44, no. 7, pp. 608-615, 2010.

[14] S. Naseem and S. Munaf, "Suicidal Ideation, Depression, Anxiety, Stress, And Life Satisfaction Of Medical, Engineering, And Social Sciences Students," Journal of Ayub Medical College, Abbottabad : JAMC, vol. 29, no. 3, pp. 422-427, 2017.

[15] D. Gerrard, K. Newfield, N. Balouchestani Asli, and C. Variawa, Are Students Overworked? Understanding the Workload Expectations and Realities of First-Year Engineering. ASEE, 2017, ch. ASEE Annual Conference \& Exposition. [Online]. Available: 10.18260/1-2-27612

[16] M. Deziel, D. Olawo, L. Truchon, and L. Golab, "Analyzing the mental health of engineering students using classification and regression," 2013. [Online]. Available: uwaterloo.ca/data-systemsgroup/publications/analyzing-mental-health-engineering-students-using

[17] A. S. Negi, A. Khanna, and R. Aggarwal, "Psychological health, stressors and coping mechanism of engineering students," International Journal of Adolescence and Youth, vol. 24, no. 4, pp. 511-520, 2019. [Online]. Available: https://doi.org/10.1080/02673843.2019.1570856

[18] P.-H. P. Hsieh, J. R. Sullivan, D. A. Sass, and N. S. Guerra, "Undergraduate engineering students' beliefs, coping strategies, and academic performance: An evaluation of theoretical models," The Journal of Experimental Education, vol. 80, no. 2, pp. 196-218, 2012. [Online]. Available: https://doi.org/10.1080/00220973.2011.596853

[19] S. Ivancevic, T. Ivanović, M. Maričić, and M. Cudanov, "Student heavy work investment, burnout, and their antecedents: The case of serbia," 2020.

[20] B. E. Compas, J. K. Connor-Smith, H. Saltzman, A. H. Thomsen, and M. E. Wadsworth, "Coping with stress during childhood and adolescence: problems, progress, and potential in theory and research," Psychol Bull., vol. 12, no. 1, pp. 87-127, 2001.

[21] N. K. Balaji, P. S. Murthy, D. N. Kumar, and S. Chaudhury, "Perceived stress, anxiety, and coping states in medical and engineering students during examinations," Ind Psychiatry J., vol. 28, no. 1, pp. 86-97, 2019.

[22] StatsSA, "Youth still find it difficult to secure jobs in south africa," Quaterly Labour Force Survey, 2020-11-17. [Online]. Available: http://www.statssa.gov.za/?p=14415

[23] T. Reddy and A. Sokomani, "Youth still find it difficult to secure jobs in south africa," Institute for Security Studies, vol. 154, Nov 
2008. [Online]. Available: https://issafrica.org/chapter-2-overview-ofthe-south-african-social-security-system

[24] C. Hodges, S. Moore, B. Lockee, T. Trust, and A. Bond, "The Difference between Emergency Remote Teaching and Online Learning," Educause Review, vol. 27, 2020.

[25] R. Barnett, "University knowledge in an age of supercomplexity," Higher Education, vol. 40, no. 4, pp. 409-422, 2000. [Online]. Available: https://link.springer.com/article/10.1023/A:1004159513741

[26] A. Tait, "Planning Student Support for Open and Distance Learning," Open Learning: The Journal of Open, Distance and e-Learning, vol. 15, no. 3, pp. 287-299, 2000.

[27] J. Gilmore, K. Wolff, and M. Bladergroen, "The night before the test: Electrical engineering students' use of online resources to prepare for assessment," Proceedings of the 4th Biennial Conference of the South African Society for Engineering Education, Jun 2017.

[28] C. Lewis, K. Wolff, and B. Bekker, "Supporting project-based education through a community of practice: a case of postgraduate renewable energy students," World Transactions on Engineering and Technology Education, vol. 19, no. 1, pp. 35-40, 2021.

[29] K. Wolff, "Teaching cannot live on technology alone," Mail \& Guardian, 2020-11-17. [Online]. Available: https://mg.co.za/opinion/2020-11-17teaching-cannot-live-on-technology-alone/

[30] D. D. Pratt, Five perspectives on teaching in adult and higher education. Krieger Publishing, Melbourne, 1998. [Online]. Available: https://eric.ed.gov/?id=ED461013

[31] W. Morrow, Bounds of Democracy: Epistemological Access in Higher Education. HSRC Press, Pretoria, 2009. [Online]. Available: https://www.hsrcpress.ac.za/books/bounds-of-democracy

[32] H. Hanrahan, Knowledge, expertise and the professions. Routledge, 2014, ch. The evolution of engineering knowledge, pp. 119-137. [Online]. Available: https://www.taylorfrancis.com/chapters/edit/10.4324/9781315883083-

17/evolution-engineering-knowledge-hu-hanrahan

[33] I. Scott, Higher education in South Africa. A scholarly look behind the scenes. African SUN Media, 2009, ch. Academic development in South African higher education. [Online]. Available: $10.18820 / 9781920338183$

[34] L. Czerniewicz, N. Agherdien, J. Badenhorst, D. Belluigi, T. Chambers, M. Chili, M. de Villiers, A. Felix, D. Gachago, C. Gokhale, E. Ivala, N. Kramm, G. M. Matete Madiba, E. Mgqwashu, N. Pallitt, P. Prinsloo, K. Solomon, S. Strydom, M. Swanepoel, F. Waghid, and G. Wissing, "A Wake-Up Call: Equity, Inequality and Covid-19 Emergency Remote Teaching and Learning," Postdigital Science and Education, vol. 2, p. 946-967, 2020. 